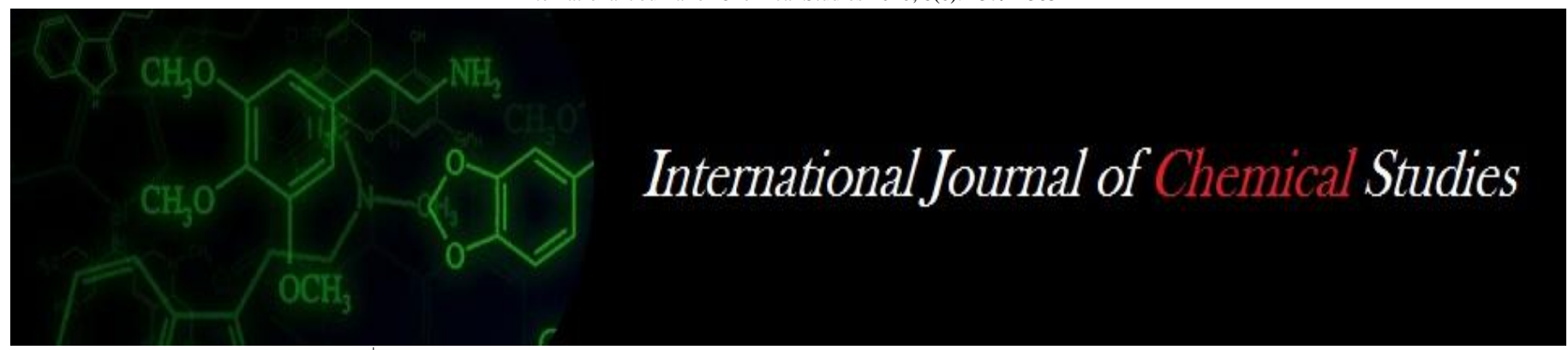

P-ISSN: 2349-8528

E-ISSN: 2321-4902

www.chemijournal.com

IJCS 2020; 8(6): 1379-1383

(C) 2020 IJCS

Received: 05-09-2020

Accepted: 08-10-2020

\section{Shaikh Shaizad}

Department of Food Process,

Technology MIP College of Food

Technology Vasantrao Naik

Marathwada Krishi Vidyapeeth,

Parbhani, Maharashtra, India

\section{Shaikh Ajaj}

Department of Food Process

Technology, MIP College of Food

Technology Vasantrao Naik

Marathwada Krishi Vidyapeeth,

Parbhani, Maharashtra, India

\section{SK Sadawarte}

Department of Food Process Technology, College of Food

Technology Vasantrao Naik Marathwada Krishi Vidyapeeth,

Parbhani, Maharashtra, India

GM Machewad

Department of Food

Microbiology and Safety, College

of Food Technology Vasantrao

Naik Marathwada Krishi

Vidyapeeth, Parbhani,

Maharashtra, India

\section{Shinde EM}

Department of Food

Microbiology and Safety, College

of Food Technology Vasantrao

Naik Marathwada Krishi

Vidyapeeth, Parbhani,

Maharashtra, India

\section{AR Sawate}

College of Food Technology

Vasantrao Naik Marathwada

Krishi Vidyapeeth, Parbhani,

Maharashtra, India

\section{AK Singh}

Department of Food Process

Engineering, SHUATS,

Allahabad, Uttar Pradesh, India

\section{Corresponding Author:}

\section{Shaikh Ajaj}

Department of Food Process

Technology, MIP College of Food

Technology Vasantrao Naik

Marathwada Krishi Vidyapeeth,

Parbhani, Maharashtra, India

\section{Studies on standardization, quality assessment of herbal tea with incorporated moringa olefera leaf powder}

\author{
Shaikh Shaizad, Shaikh Ajaj, SK Sadawarte, GM Machewad, Shinde EM, \\ AR Sawate and AK Singh
}

DOI: https://doi.org/10.22271/chemi.2020.v8.i6t.10951

\begin{abstract}
The present investigation was aimed to development of herbal tea with incorporation of different proportions moringa olefera leaf powder. To standardize the processing technology and analyze the characteristics of herbal tea viz., chemical and sensory characteristics of herbal tea. The formulation was carried out using moringa olefera leaf powder, basil, lemon grass and tea powder in Preparation of herbal tea. Different formulation was made with variation in moringa olefera leaf powder level from 0 to $50 \%$ for $T_{0}, T_{1}, T_{2}, T_{3}$ and $T_{4}$ respectively. Prepared herbal tea then evaluated for organoleptic properties with respects to colour and appearance, flavour, texture, taste and overall acceptability using 9 point hedonic scale. The results revealed that herbal tea prepared with supplementation of $50 \%$ moringa olefera leaf powder (T1) secured highest score (i.e. 8.0) was superior as compared to rest of samples. It was found that moringa olefera leaf powder prepared with moringa olefera was rich source of proteins. Thus, moringa olefera can be well utilized as a functional ingredient for preparation of herbal tea with good nutritional and medicinal value.
\end{abstract}

Keywords: Moringa olefera, herbal tea, sensory evaluation

\section{Introduction}

The drinking of tea begun in China centuries ago, and has over the years become an inseparable part of most cultures worldwide. Tea is currently the most widely consumed beverage in the world ${ }^{[21]}$ and therefore ranks as an important world food product. Tea is generally consumed for its attractive aroma and taste as well as the unique place it holds in the culture of many societies. In recent times, there is renewed interest in tea because of growing consumer awareness of health benefits derived from tea consumption. Tea therefore belongs to

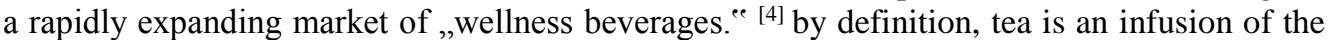
leaves or other parts of the evergreen tea plant (Camellia $s p$ ). Teas have been traditionally categorized into green, oolong and black teas according to the processing conditions employed during manufacturing. ${ }^{[11]}$ In recent times, however, a fourth category, called herb teas, is gaining increasing popularity among consumers. Unlike traditional teas, herb teas are prepared from plants other than Camellia ${ }^{[3]}$. Tea preparation follows a simple procedure. Hot water (70 ${ }^{\circ} \mathrm{C}$ to $100{ }^{\circ} \mathrm{C}$ ) is poured over the plant part(s) in a container and allowed to steep for a few minutes (usually $1-5 \mathrm{~min}$ ) after which the plant material, usually contained in a bag, is removed from the container. The temperature of the water used and the duration of steeping affect the ,strengthe of the tea. Tea is drunk hot, warm or iced. In some cases milk and/or a sweetener such as honey or sucrose may be added before drinking ${ }^{[10]}$.

Tea is the processed leaves of Camellia sinensis which upon infusion with cold or hot water, gives a non-alcoholic beverage ${ }^{[22]}$. Tea consumption is a very ancient habit, with legends from China and India indicating that it will initiated about five thousand years ago ${ }^{[7]}$ Traditionally, tea will consumed to improve blood flow, eliminate toxins and improve resistance to diseases . Polyphenols are the most biologically active group of tea components ${ }^{[11]}$ which possesses antioxidative, antimutagenic and anticarcinogenic effects ${ }^{[26]}$ modified polyphenol content and composition of yerba mate as well as the capacity of its extracts to inhibit the oxidation of $\beta$ carotene/linoleic acid system, after industrial processing. 
Tea is the mostly used daily beverage throughout the world, with estimated daily consumption of more than 3 billion cups ${ }^{[5]}$. It is valued due to potential health benefits confirmed with preclinical and epidemiological studies, its aroma content, and cultural association. There is increasing demand of tea extract and isolated tea biomolecules. In pharmaceutical and food industries as natural antioxidant andforotheruses. Tea biomolecules mainly consists of non protein amino acid theanine, free sugars ${ }^{[24]}$, methylxanthine or purine alkaloid like caffeine, theobromine, theophylline and theacrine, phenolic acids like gallic acid, and eight other catechins ${ }^{[18]}(-)$-epicatechin (EC), (-)-epigallocatechin (EGC), (-)epicatechin- 3-gallate (ECG), and (-)-epigallocatechin- 3gallate (EGCG) are the main catechin of green tea. Cumulatively they are often called as polyphenols. Though EGCG is the major tea catechin with most anticarcinogenic property, EGC has highest antioxidant efficacy followed by EGCG, EC, and ECG respectively ${ }^{[14]}$.

Nowadays decaffeinated tea is more preferred because caffeine causes irritation in gastrointestinal tract, sleeplessness, cerebral cortex stimulation and excites central nervous system in people ${ }^{[26]}$ Still awareness of the antioxidant properties and other health benefit like anti carcinogenic and chemopreventive effect ${ }^{[8]}$ anti-hyperglycemic effect ${ }^{[9]}$ antiobesity effects ${ }^{[13]}$ anti diabetic ${ }^{[20]}$ antiulcereffects. ${ }^{[16]}$ These attributes designates tea polyphenols as functional food too. ${ }^{[15]}$ The components responsible for sensory attributes are z-3hexanol, benzyl alcohol, linalool, 2- pheylethanol, methyl salicylate, geraniol, nerolidol ${ }^{[25]}$, Black tea requires complete fermentation of leaves while oolong tea is partially fermented during processing. Utilization of tea biomolecules in food industry. It is used in chewing gums for halitosis and preventing dental caries. Ltheanine, having umami taste is used for taste masking in foods ${ }^{[7]}$. Heterocyclic aromatic amines (HA) are considered as food generated carcinogen, obtained from meat and produced during meat cooking. It was found that green tea marinade not only reduce HA content by its free radical scavenging property, but also modifies the taste of panfried meat and can be used as non alcoholic marinade too

Developing new herb tea products from indigenous plants will provide novel uses for Underutilized plants. It will further provide consumers with new alternatives to traditional teas. Moreover the research will bring to light the potential of the underutilized plants for food product development. The research will broaden understanding of the sensory characteristics and preferences of herb teas in particular and beverages in general. It will further advance research in herb tea product development. In view of the above facts the production of herbal tea from moringa oleifera leaf powder fortified with basil, lemon grass and tea leaf powder were studied.

\section{Materials and Methods \\ Materials}

The Raw material like moringa olefera leaves, basil, lemon grass and tea leaves etc. will be procured from the local market of allahabad. Chemical and reagent will be obtained from laboratory, Department of Food process engineering, SHUATS Allahabad.

\section{Methods \\ Preparation of Moringa leaf powder}

The fresh raw Moringa leaves were selected by visual appearance of fresh and dark coloured, fully matured without any physical damage, on the surface. Then the collected Moringa leaves were washed by pure water for removing of the dust. Then after Moringa leaf sample was placed in the dryer maintained at the temperature of $60{ }^{\circ} \mathrm{C}$ for drying as per the requirement to obtain bone dry product. Then grinding of the dried Moringa leaf was done by the grinder to obtain Moringa powder. Sieving was done by the 32 number sieve size screen to obtain fine powder of the grounded Moringa leaf powder. By following the above procedure, the fine Moringa powder was obtained. The fine Moringa powder was then packed in the LDPE packing bags for the further storage.

\section{Preparation of Basil leaf powder}

The fresh leaves of Basil were selected by visual appearance; the leaves were washed by pure water for removing of the dust and soil. The leaves were detaches from branches. After that basil leaves were placed in the dryer maintained at the temperature of $70{ }^{0} \mathrm{C}$ for drying as per the requirement to obtain bone dry product. Grinding of the dried leaves was done by the grinder to obtain basil powder. Sieving was done by the 32 number sieve size screen to obtain fine powder of the grounded basil powder. By following the above procedure, the fine basil powder was obtained. The fine basil powder was then packed in the LDPE packing bags for the further storage.

\section{Preparation of Lemon grass leaf powder}

The fresh leaves of lemongrass were selected by visual appearance of fresh and dark coloured, fully matured without any physical damage, on the surface. Then the collected lemon grass leaves were washed by pure water for removing of the dust. Then after lemongrass leaf sample was placed in the dryer maintained at the temperature of $70{ }^{\circ} \mathrm{C}$ for drying as per the requirement to obtain bone dry product. Then grinding of the dried lemongrass leaf was done by the grinder to obtain lemongrass powder. Sieving was done by the 32 number sieve size screen to obtain fine powder of the grounded lemongrass leaf powder. By following the above procedure, the fine lemongrass leaf powder was obtained. The fine lemongrass leaf powder was then packed in the LDPE packing bags for the further storage.

\section{Preparation of Tea Bags}

The tea bags material was made using heap fill tea bags filter paper. The filter paper was been cut with a pair of scissors into rectangular shapes of $12 \times 10 \mathrm{~cm}$ after which it was been folded and the two sides was sealed with an electrical hand heat sealing machine and then was refilled with the crushed dried Moringa Herbal tea powder and then the top was also sealed by passing a thread (piece of string) that served with a paper label attached to the tea bag as a handle for dipping in the water after filling with $2 \mathrm{~g}$ of each bag.

\section{Determination of minerals composition of herbal tea}

Raw materials such moringa olefera leaves, basil, lemon grass, tea leaves and herbal tea were analyzed for proximate composition including moisture, fat, protein, total carbohydrate, crude fiber, ash and mineral composition was carried out as per the methods given by AOAC, 2005.

\section{Determination of minerals composition of herbal tea}

Two grams of defatted sample was weighed and heated at 550 ${ }^{\circ} \mathrm{C}$. Then, the obtained ash were digested with concentrated Hydrochloric acid (HCL) on hot plate. The digested material was then filtered using whatman No. 42 filter paper and the 
final volume made to $100 \mathrm{ml}$ with distilled water that was further used for analysis with respects to iron, calcium, potassium, contents by using methods Ranganna (1986).

Table 1: Formulation of herbal tea incorporated with moringa olefera leaf powder

\begin{tabular}{|c|c|c|c|c|c|}
\hline Ingredient & $\mathbf{T}_{\mathbf{0}}$ (Control) & $\mathbf{T}_{\mathbf{1}}$ & $\mathbf{T}_{\mathbf{2}}$ & $\mathbf{T}_{\mathbf{3}}$ & $\mathbf{T}_{\mathbf{4}}$ \\
\hline Moringa leaf powder (\%) & 0 & 50 & 40 & 30 & 20 \\
\hline Basil leaf powder (\%) & 65 & 15 & 25 & 35 & 45 \\
\hline Lemon grass powder (\%) & 25 & 25 & 25 & 25 & 25 \\
\hline Tea leaf powder (\%) & 10 & 10 & 10 & 10 & 10 \\
\hline
\end{tabular}

\section{Microbiological evaluation}

The microbial analysis of fresh Herbal tea samples was determined by method given by using As per the WHO (1994) guideline. The powder was examined for microbial contamination. Total viable count of the final powder was determined by using standard plate count technique $(0.1 \mathrm{ml})$ of the appropriate dilution was placed on nutrients agar plates. The plates were incubated at $35{ }^{\circ} \mathrm{C}$ for $48 \mathrm{hr}$ and colony forming units per gram sample (cfu/gm) was estimated.

For mould and yeast count; the above procedure was repeated using potato dextrose agar and incubation was done at $25{ }^{\circ} \mathrm{C}$ for $72 \mathrm{hrs}$.

$S P C(c f u / m l)=$ Average no. of colonies $\times$ reciprocal of the dilution used. ------------ (Eq. 3.8)

\section{Results and Discussion}

Evaluation of quality characteristics of developed Herbal tealPhysical properties of developed Herbal Tea

The developed Moringa Herbal Tea was analyzed for their physical properties. It is widely used during processing of tea to determine the sugar concentration in the products. Developed Herbal Tea was also analyzed Colour, flavour, Texture.

Table 2: Physical properties of developed Moringa Herbal Tea

\begin{tabular}{|c|c|}
\hline Parameters & Value \\
\hline TSS (0 Bx) & 4 \\
\hline PH & 5.0 \\
\hline
\end{tabular}

\section{Chemical analysis of developed Moringa Herbal Tea}

Chemical composition represents the nutritional quality of product. Analysis of proximate composition of Moringa Herbal tea decides the nutritional profile of prepared tea powder, as Moringa is a novel ingredient. The proximate composition of developed Herbal tea was determined in dry weight basis and the results are discussed in Table.

Table 3: Chemical analysis of developed Moringa Herbal Tea

\begin{tabular}{|c|c|c|c|c|c|c|}
\hline $\begin{array}{c}\text { Sr. } \\
\text { No. }\end{array}$ & $\begin{array}{c}\text { Chemical Composition } \\
\text { Value Per (100gm) }\end{array}$ & T0 & T1 & T2 & T3 & T4 \\
\hline 1 & Moisture (\%) & 8.63 & 8.95 & 8.77 & 8.43 & 9.12 \\
\hline 2 & Ash (\%) & 1.35 & 1.56 & 3.78 & 3.06 & 1.97 \\
\hline 3 & Total Protein (\%) & 7.43 & 8.13 & 10.47 & 10.98 & 9.86 \\
\hline 4 & Total Carbohydrate & 9.63 & 12.48 & 10.91 & 12.74 & 12.87 \\
\hline 5 & Crude Fat (\%) & 5.21 & 5.63 & 4.83 & 3.74 & 2.68 \\
\hline 6 & Calcium(mg/100gm) & 216.36 & 245.21 & 139.47 & 174.92 & 254.1 \\
\hline 7 & Fe (mg/100gm) & 8.23 & 9.12 & 9.77 & 8.91 & 9.83 \\
\hline
\end{tabular}

It is observed from the Table- that its moisture content was found to be $8.63,8.95,8.77,8.43$, and 9.12 percent. The fat content was found to be $5.21,5.63,4.89,3.74$, and 5.94 per cent. The protein content was found to be $7.43,8.43,10.47$,
10.98, and 9.86 per cent. The ash content was found to be $1.35,1.56,3.78,3.06$, and 1.97 per cent. The calcium Ca $(\mathrm{mg} / 100 \mathrm{~g})$ content was found to be $216.36,245.21,139.47$, 174.92 , and 254.17 per cent. The iron $\mathrm{Fe}(\mathrm{mg} / 100 \mathrm{~g})$ content was found to be $8.23,9.12,9.77,8.91$, and 9.53 per cent.

\section{Organoleptic evaluation of herbal tea}

The judgment was made by rating product on a 9-point hedonic scale with corresponding descriptive term ranging from 9 "like extremely" to "dislike extremely" to determine the pleasurable and un pleasurable feel of Moringa Herbal tea. 10 untrained panelists aged between 18-35 years participated in the consumer test conducted at the department of Food Process Engineering, Sam Higginbottom University of Agriculture, Technology and Sciences. Samples showed more acceptances as compared to other samples.

Table 4: Sensory Evaluation of herbal tea incorporated with moringa olefera leaf powder

\begin{tabular}{|c|c|c|c|c|c|}
\hline \multirow{2}{*}{ Treatments } & \multicolumn{5}{|c|}{ Sensory Characteristics } \\
\cline { 2 - 6 } & Colour & Taste & Flavour & Appearance & $\begin{array}{c}\text { Overall } \\
\text { Acceptability }\end{array}$ \\
\hline $\mathrm{T}_{0}$ & 9.0 & 9.0 & 9.0 & 9.0 & 9.0 \\
\hline $\mathrm{T}_{1}$ & 7.6 & 7.38 & 7.2 & 7.1 & 7.4 \\
\hline $\mathrm{T}_{2}$ & 7.21 & 6.94 & 6.77 & 6.68 & 6.98 \\
\hline $\mathrm{T}_{3}$ & 7.0 & 7.0 & 6.7 & 6.8 & 7.18 \\
\hline $\mathrm{T}_{4}$ & 7.15 & 7.0 & 6.8 & 6.9 & 7.3 \\
\hline
\end{tabular}

Organoleptic quality parameters of a product assume pivotal role in anticipating the consumer response to the product. On the basis of organoleptic evaluation of Moringa Herbal tea, samples were selected as best sample. The percent of Moringa was used separately in different proportions (50, 15,25 and 10 per cent) in Herbal tea with Basil, Lemon grass and tea leaves proportion. The formulated Moringa based Herbal tea was further organoleptically analyzed for quality attributes like colour, flavour, taste, appearance and overall acceptability. The data pretaining to organoleptic evaluation of Moringa based tea are presented in Table

Note:

$\mathrm{T} 0=10 \%$ (Tea leaves powder)

$\mathrm{T} 1=50 \%$ Moringa powder;

$\mathrm{T} 2=40 \%$ Moringa powder;

$\mathrm{T} 3=30 \%$; Moringa powder;

$\mathrm{T} 4=20 \%$ Moringa powder.

The data pertaining to the sensory scores of appearance, colour, flavor, taste, texture and overall acceptability of Herbal tea prepared of Moringa oleifera with different proportions is given in the Table. A significant difference was observed for the scores obtained for Moringa Herbal tea for all the sensory parameters. Mean colour scores ranged from 6.5 to 9 with a mean of 7.55. The mean flavour scores ranged from 6.1 to 9 , with mean of 7.15. The mean taste score ranged from 6.3 to 9 , with a mean of 7.2. The mean overall acceptability scores ranged from 6.4 to 9 , with mean of 7.36 . From ANOVA table was evident that the calculated value of F (118.547) due to treatment was greater than the tabulated value at 5 percent probability level (5.585).therefore it concluded that significant effect of treatment on moisture content of T1 sample was observed at interval of 20 days during the storage period. (Table 4) 


\section{Microbial analysis of herbal tea}

Microbial analysis was done to study the microbial quality of Moringa Herbal tea powder by using pour plate technique. The analysis was done at the interval of one month after the preparation of Moringa Herbal tea powder with concentration of lemon grass was kept constant. From Table, it can be concluded that samples of Moringa Herbal tea powder with 60 days storage period tend to have higher mean bacterial counts $3.8 \times 10^{5} \mathrm{CFU} / \mathrm{g}$ than those with 40 days $1.93 \times 10^{5}$ $\mathrm{CFU} / \mathrm{g}$ and 20 days $1.48 \times 10^{3} \mathrm{CFU} / \mathrm{g}$.

Table 5: Microbial analysis of Herbal Tea

\begin{tabular}{|c|c|c|c|}
\hline $\begin{array}{c}\text { Sr } \\
\text { No. }\end{array}$ & $\begin{array}{c}\text { Storage period } \\
\text { (days) }\end{array}$ & $\begin{array}{c}\text { Total bacterial } \\
\text { count }(\mathbf{C F U} / \mathbf{g})\end{array}$ & $\begin{array}{c}\text { Total yeast and mould } \\
\text { count }(\mathbf{C F U} / \mathbf{g})\end{array}$ \\
\hline 1 & 20 days & $1.72 \times 10^{4}$ & $1.2 \times 10^{3}$ \\
\hline 2 & 40 days & $2.22 \times 10^{4}$ & $1.9 \times 10^{3}$ \\
\hline 3 & 60 days & $2.40 \times 10^{4}$ & $2.45 \times 10^{3}$ \\
\hline
\end{tabular}

Total yeast and mould counts were highest $2.40 \times 10^{4}$ (CFU/g) in 60 days stored Herbal tea than 40 days $2.22 \times 10^{4}$ (CFU/g) and 20 days $1.72 \times 10^{4} \mathrm{CFU} / \mathrm{g}$. There was growth of molds on the surface of Moringa Herbal tea with 60 days storage period. The growths of bacteria, yeast and mould were in increasing order as storage period increased. As per the WHO (1994) guideline the total plate count, and Yeast and mould count should be less than $2 \times 105$ and $1 \times 10^{4}$ per gram respectively.

\section{Conclusion}

It can be concluded from results that herbal tea prepared with 50:15:25:10 proportions of moringa olefera leaves powder, basil leaf powder, lemon grass powder and tea leaves powder was found to highly acceptable and recorded maximum score in case of all the sensory attributes. The combination of different herbs gave good result i.e. excellent source of Protein, Carbohydrate and Minerals content. Formulated Herbal tea not only fulfills the nutritional parameters, but also got best response of sensory parameters from panel members and from consumers.Thus, Moringa olefera can be well utilized as a functional ingredient for preparation of herbal yea with good nutritional and medicinal value which act as functional food product.

\section{References}

1. AOAC. Official Methods of Analysis of the AOAC International, 18thed. Association of Official Analytical Chemists, Gaithersburg, MD 2005.

2. Anwar F, Latif S, Ashraf M, Gilani AH. A Food Plant with Multiple Medicinal Uses. Phytotherapy Research 2007;21:17-25.

3. Bender DA. Benders ${ }^{e e}$ Dictionary of Nutrition and Food Technology, 7th Edition, CRC Press 2003.

4. Byun, JO, Han JS. Study perception and actual status of utilization for green tea. Korean Journal of Food Culture 2004;18:184-192.

5. Chen L, Zhou ZX. Variations of main quality components of tea genetic resources [Camellia sinensis (L) O Kuntze] preserved in the China National Germplasm Tea Repository. Plant Foods Human Nutrition 2005;60(1):31-35.

6. Cock de .evaluation of diffussivity and acceptable mixing ratio for production of hibiscus-moringa tea bags. Arid zone Journal of Engineering, Technology and Environment 2005-17;13(4):513-522.
7. Dufresne CJ, Farnworth ER. Review of latest research findings on the health promotion properties of tea. Journal Nutrition Biochemistry 2001;12(7):404-421.

8. Fujiki H. Green Tea health benefits as cancer preventive for humans. Chemestry 2005;5(3):119-132.

9. Gornes A, Vedasiromoni JR, Das M, Sharma RM, Ganguly DK. Anti hyperglycemic effect of black tea (Camellia sinensis) in ratinol Journal Ethno pharmacol 1995;45(3):223-226.

10. Hakim IA, Weisgerber UM, Harris RB, Balentine D, Mierlo CAJ, Paetau Robinson I. Preparation, composition and consumption patterns of tea-based beverages in Arizona. Nutrition Research. 2000;20(12):1715-1724.

11. Kirk RS, Sawyer R. Pearson"s Composition and Analysis of Foods (9th Ed) Longman Singapore Publishers; Singapore 1997,356-362.

12. Kumudavally KV, Phanindrakumar HS, Tabassum A, Radhakrishna K, Bawa AS. Green tea-A potential preservative for extending the shelf life of fresh mutton at ambient temperature $\left(25 \pm 2^{\circ} \mathrm{C}\right)$. Food Chemistry 2008;107(1):426-433.

13. Lin JK, Lin-Shiau SY. Mechanisms of hypolipidemic and anti-obesity effects of tea and tea polyphenols. Molecular Nutrition Food Research 2006;50(2):211-217.

14. Lu MJ, Chen C. Enzymatic modification by tannase increases the antioxidant activity of green tea. Food Research 2008;41(2):130-137.

15. Liang $\mathrm{H}$, Liang $\mathrm{Y}$, Dong J, Lu J, Xu H, Wang $\mathrm{H}$. Decaffeination of fresh green tea leaf (Camelliasinensis) by hot water treatment. Food Chemistry 2007;101(4):1451-1456.

16. Maity S, Vedasiromoni JR, Ganguly DK. Anti-ulcer effect of the hot water extract of black tea (Camelliasinensis). Journal of Entimation thnopharmacol 1995;46(3):167-174.

17. Park HS, Im NG, Kim KH. Extraction behaviors of caffeine and chlorophyll sinsuper critical decaffeination of green tea leaves. Food Sciene Technology 2012;45(1):73-78.

18. Peng L, Song X, Shi X, Li J, Ye C. Animproved HPLC method for simultaneous determination of Phenolic compounds purine Journal Food Sci Technol (2015) 52(6):3158- 31683167 alkaloids and theanine in Camellia species 2008;21(7): 559-563.

19. Ranganna S. Handbook of Analysis and Quality Control for Fruit and vegetables Products. Second Edition. Tata McGraw Hill Publishing Limited, New Delhi 1986.

20. Sabu MC, Smitha K, Kuttan R. Anti-diabetic activity of green tea polyphenols and their role in reducing oxidative stress in experimental diabetes. Journal Ethno pharmacol 2002;83(1-2):109-116.

21. Schmidt M, Schmitz HJ, Baumgart A, Guedon D, Netsch MI, Kreuter MH. Toxicity of green tea extracts and their constituents in rat hepatocytes in primary culture. Food Chemistry Toxicolog 2005;43:307-14.

22. Sharma V, Gulati A, Ravindranath SD. Eextractability of tea catechins as a function of manufacture procedure and temperature of infusion. Food Chemistry 2005;93(1):141148.

23. Park HS, Im NG, Kim KH. Extraction behaviors of caffeine and chlorophyll sinsuper critical decaffeination of green tea leaves. Food Sciene Technology 2012;45(1):73-78.

24. Unachukwu UJ, Ahmed S, Kavalier A, Lyles JT, Kennelly EJ. White and Green Teas (Camellia sinensis 
varsinensis): variation in phenolic methylxanthine and antioxidant profiles. Journal Food Science 2010;75(6):C541-C548.

25. Xia T, Shi S, Wan X. Impact of ultrasonic-assisted extraction on the chemical and sensory quality of tea infusion. Food Engineering 2006;74(4):557-560.

26. Ye H, Liang YR, Jin J, Liang HL, Du YY, Lu JL et al. preparation of partially decaffeinated instant green tea. Journal Agriculture Food Chemestry 2007;55(9):34983502 . 